\title{
O desenho técnico do vestuário sob a ótica do modelista
}

The technical drawing of clothes through the eyes of the patternmaking professional

\author{
SUONO, Celso Tetsuro; Mestre em Desenho Industrial; \\ Universidade Tecnológica Federal do Paraná \\ suono@utfpr.edu.br
}

\begin{abstract}
Resumo
A presente pesquisa tem como proposta verificar a validade dos princípios e fundamentos existentes na construção do desenho técnico do vestuário junto aos profissionais da área de modelagem das instituições de ensino superior e das indústrias de confeç̧ão. O campo desse estudo é delimitado por profissionais que atuam como docentes e modelistas nas cidades de Londrina e Maringá, região Norte do Paraná, utilizando como estratégia a aplicação de uma pesquisa qualitativa e de caráter exploratório, descrevendo as opiniões dadas pelos agentes participantes. Apresenta os resultados de forma indutiva, fazendo o cruzamento dos dados e comparando-os simultaneamente entre os dois grupos entrevistados. Em seguida, levanta os principais aspectos a serem discutidos de acordo com as variáveis apontadas e, ao final traz as conclusões pertinentes para essa investigação.
\end{abstract}

Palavras Chave: Representação gráfica; Moda; Desenho técnico do vestuário.

\begin{abstract}
The proposal in this research is to verify the validity of principles and bases concerned with the technical drawing of clothes among the professionals of the patternmaking area from higher education and clothing industries. The corpus of this study consists of professionals who work as professors and modelists in the cities of Londrina and Maringá, North of Paraná. This is a qualitative research with an exploratory character, describing the subjects'opinions. It presents the findings inductively, crossing and comparing data simultaneously from the two groups. As a further step, this study raises the main issued to be discussed according to the variables pointed out and, finally, it brings meaningful conclusions to this investigation.
\end{abstract}

Keywords: Graphic representation; Fashion; Technical drawing of clothes.

\section{Introdução}

Nos últimos anos, além do seu reconhecimento como pólo produtivo, o Brasil passou a ser considerado como pólo criativo emergente de moda, tanto no contexto nacional como internacional. Esse panorama da moda brasileira traz reflexos significativos quanto à atuação do profissional no mundo globalizado e exige que ele busque conhecimentos para sua qualificação. Entende-se, assim, que a capacitação constante torna-se fator indispensável para que o profissional conquiste mais oportunidades de trabalho.

O surgimento de novos cursos na área de moda nas instituições de ensino cresce em todo país. A maioria desses cursos possui uma estrutura curricular bastante semelhante, que varia conforme as diretrizes estabelecidas pela instituição para atender as necessidades locais de cada região. Fato curioso a ser observado é que a disciplina de desenho se faz presente sempre em todas as grades disciplinares dos cursos. 


\section{Celso Tetsuro Suono}

Percebe-se, que existe uma atenção especial dada a essa disciplina durante a implantação de cursos nas instituições de ensino. É provável que esse fato aconteça devido à possibilidade do desenho ser considerado um dos meios mais rápidos, baratos e eficazes na comunicação das idéias de projeto.

O desenho do vestuário pode ser desenvolvido de maneira mais artística, por meio de uma representação denominada desenho de estilo. Contudo, a maior parte das empresas prefere trabalhar com uma representação mais técnica, ou seja, o desenho técnico.

Por ser tratar de uma linguagem gráfica e de um instrumento de comunicação de projeto, o desenho técnico deve, na medida do possível, apresentar informações precisas a respeito do produto e oferecer condições de leitura e de interpretação das especificações dadas pelo designer. Dessa maneira, o desenho técnico do vestuário deve constituir-se numa expressão clara, uma vez que ele é repassado posteriormente ao profissional da área de modelagem, encarregado pela materialização da peça.

Nota-se na indústria de moda que o designer encontra algumas dificuldades para representar de maneira clara e objetiva as informações do produto pela linguagem gráfica. Devido a esse fato, o modelista tem dificuldades para ler e interpretar os dados do desenho técnico do vestuário durante o desenvolvimento de suas tarefas.

Baseado nisso, a falta de estudos científicos mais expressivos que abordem questões referentes aos problemas no processo de comunicação entre designers e modelistas por meio do desenho técnico do vestuário constitui-se no problema central desse estudo.

A importância dessa pesquisa justifica-se no fato do desenho técnico apresentar-se como canal de comunicação na elaboração de projetos. É de extrema necessidade verificar eventuais falhas que comprometam o bom desempenho dos profissionais envolvidos.

Dessa forma, o presente trabalho propõe verificar a validade dos princípios e fundamentos existentes para a construção do desenho técnico do vestuário junto aos profissionais da área de modelagem, atuantes nas instituições de ensino e nas indústrias de confecção das cidades de Londrina e Maringá, região Norte do Paraná.

\section{O desenho de moda e suas relações com o profissional da área de modelagem}

O desenho de moda é subdividido em dois tipos: o desenho artístico e o desenho técnico. No processo de desenvolvimento de produtos, o desenho artístico, também denominado como croqui de estilo, normalmente é representado de maneira expressiva sobre um corpo estilizado, descaracterizado nas suas proporções reais.

Ao ser transposto para as etapas do processo produtivo na empresa, o desenho artístico (croqui de estilo) pode ser repassado para um modo de representação plana bidimensional, por meio do desenho técnico, para representar a peça de vestuário como se estivesse esticada sobre uma superfície plana. Essa transposição do desenho artístico para o desenho técnico tem como principal meta comunicar as idéias do designer aos responsáveis pelas tarefas de modelagem e pilotagem da peça.

De acordo com Fulco e Silva (2003), o desenho técnico cumpre papel importante no processo de desenvolvimento de produtos, pois além de servir como instrumento para a representação da peça de vestuário, é também responsável pela comunicação entre designer e modelista. Ainda sobre esse assunto, Rosa e Freitas (2004) observam que as informações contidas no desenho técnico devem ter alto grau de precisão e possibilitar ao profissional da área de modelagem fácil leitura e interpretação das considerações do designer em relação à

Projética Revista Científica de Design I Universidade Estadual de Londrina I V.2 I N.2 I Dezembro 2011 
O desenho técnico do vestuário sob a ótica do modelista

peça de vestuário.

O modelista é responsável pela preparação dos moldes da roupa e para essa tarefa ele deve considerar as regras de contorno anatômico do corpo. Basicamente, esses moldes são as matrizes que servem como gabarito para o corte das partes do vestuário sobre a matériaprima têxtil. Por ser um tipo de desenho com fins construtivos, o desenho técnico deve ser desenvolvido com a preocupação de apresentar na sua configuração as proporções reais do vestuário em relação ao corpo.

Para Leite e Velloso (2004), o alto grau de complexidade do desenho técnico do vestuário exige empenho e paciência na sua prática. A forte tendência da utilização do desenho técnico nas indústrias de confecção torna-se realidade cada vez mais frequente e, em função disso, a sua aplicação nas empresas se constitui também em diferencial de competitividade no mercado globalizado.

Sobre essas considerações feitas até o momento em relação à representação gráfica na área de moda, é importante ressaltar que esse assunto ainda é campo que gera muita discussão e polêmica tanto nos meios acadêmicos quanto nas indústrias de confecção. De acordo com Jones (2005), as convenções para o desenho técnico do vestuário ainda estão em fase de estudo e buscam diretrizes que conceituem a maneira mais adequada para a sua construção.

\section{Os métodos aplicados na construção do desenho técnico do vestuário}

$\mathrm{Na}$ área de moda, alguns estudos abordam aspectos sobre a construção do desenho técnico do vestuário por meio de métodos, com a finalidade de direcionar parâmetros para a sua configuração. Esses métodos são adotados pelas instituições de ensino de moda e pelos designers atuantes no mercado de trabalho, uma vez que são raras as publicações científicas direcionadas sobre o assunto. Assim, cada designer desenvolve o desenho técnico do vestuário de acordo com o conhecimento adquirido em função do método adotado.

O que é interessante observar é que, ao se comparar os vários métodos existentes, percebe-se a presença de alguns pontos de concordância ou até mesmo de divergência no que se refere às recomendações dadas pelos autores. Esse fenômeno gera confusão para o designer quanto à escolha do método mais adequado para representar esse tipo de desenho ao profissional da área de modelagem.

Dessa maneira, é importante apontar aspectos relevantes para o presente estudo no que diz respeito a essa problemática. Para essa abordagem, foram escolhidos alguns métodos e considerações propostos pelos seguintes autores: Beltrame (1990) - Itália; Takamura (1993) - Japão; Abling (1995) - EUA; Tain (1998) - EUA; Drudi e Paci (2001) - Espanha; Shimura (2002) Japão; Leite e Velloso (2004) - Brasil; Jones (2005) - Reino Unido; e Lafuente (2005) - Espanha.

a) O desenho técnico do vestuário constituído por meio de uma base:

Todos os autores concordam que o desenho técnico do vestuário deve ser desenvolvido com o auxílio de uma base. Na maioria das vezes, essa base se constitui no desenho do próprio corpo e sua configuração costuma seguir os princípios de construção do cânone (Figura 1). 


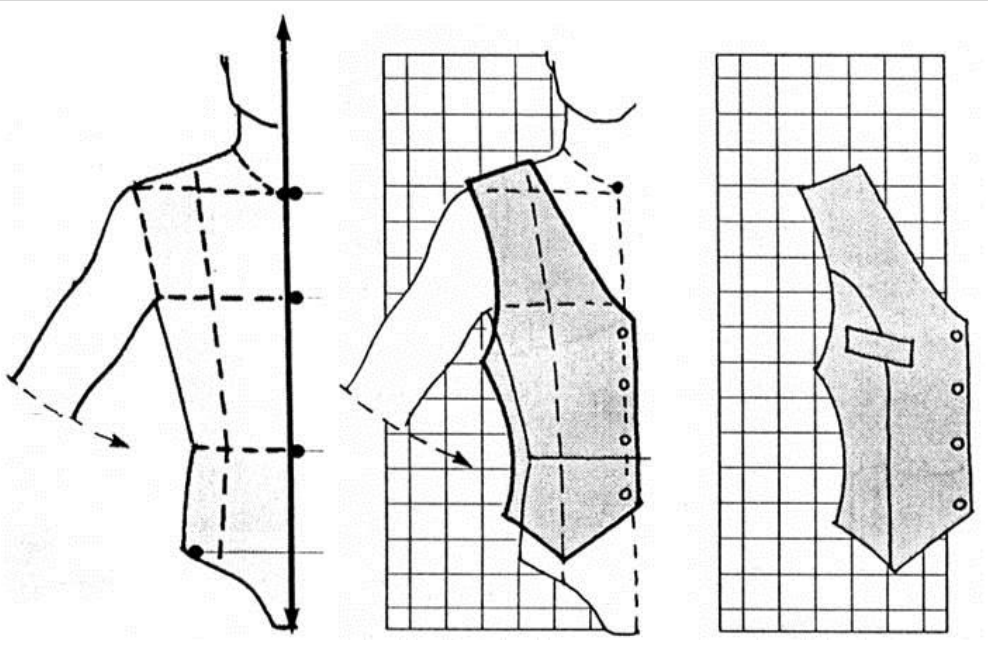

Figura 1- Construção do desenho técnico do vestuário por meio de base

Fonte: Abling (1995, p. 168)

Apesar de ser ponto comum, o que se percebe é que na sua concepção, a construção dessa base acaba seguindo parâmetros diferenciados conforme cada opinião.

Para os autores Takamura (1993), Shimura (2002) e Drudi e Paci (2001), a construção da base de corpo é constituída por meio de um cânone de oito partes e meia, em posição estática. Já no caso das americanas Abling (1995) e Tain (1998), a construção dessa mesma base parte de uma figura mais alongada, que distorce a proporção do padrão de corpo real. Em outro contexto, Leite e Velloso (2004) e Lafuente (2005) consideram que essa base deve ser desenvolvida nas proporções de uma figura mais próxima do cânone natural estabelecido pelo padrão de oito partes iguais (Figura 2).
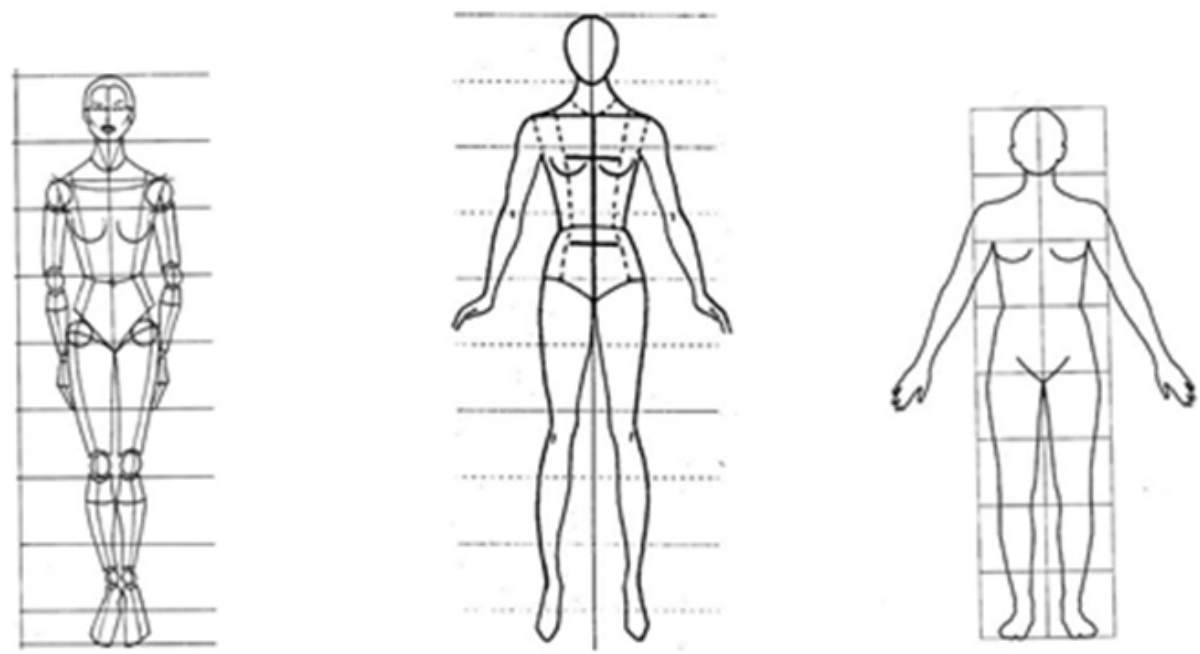

Figura 2- Base de $8 \frac{1}{2}$ partes; Base de $9 \frac{1}{2}$ partes; Base de 8 partes Fonte:Drudi; Paci, 2001, p. 18; Abling, 1995, p. 15; Leite; Velloso, 2004, p. 9

Essa diversidade de parâmetros para a construção da base do corpo consequentemente provoca relações diferenciadas na proporção da representação do vestuário e gera resultados que podem não corresponder à real configuração do produto, trazendo com isso problemas na interpretação do desenho técnico. Tain (1998) apresenta um exemplo desse fenômeno, ao comparar dois modelos idênticos construídos em bases de proporções diferentes (Figura 3).

Projética Revista Científica de Design I Universidade Estadual de Londrina I V.2 I N.2 I Dezembro 2011 

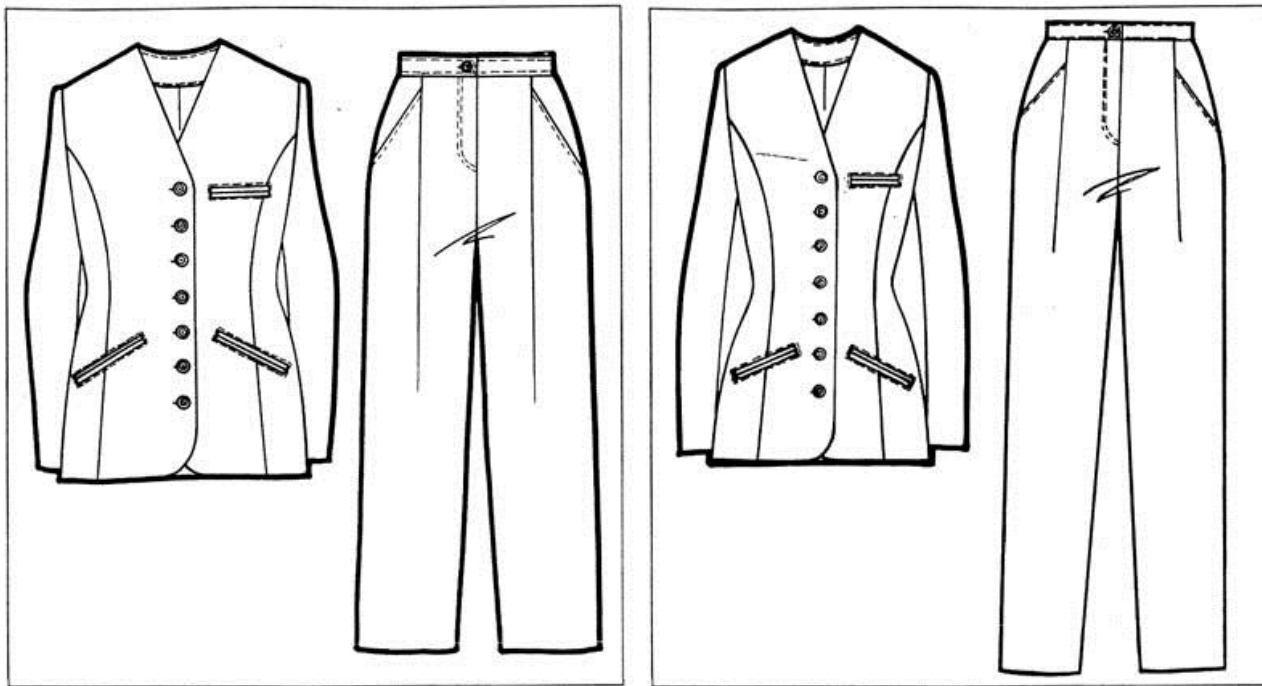

Figura 3- Interferências na proporção do desenho técnico em bases diferentes Fonte: Tain (1998, p. 90)

Existe a possibilidade também da base do desenho técnico do vestuário configurar-se em um outro tipo de estrutura que não seja necessariamente o corpo. Tain (1998), Drudi e Paci (2001), Leite e Velloso (2004) e Lafuente (2005) são alguns autores que preferem substituir a base de corpo por uma base de manequim técnico (Figura 4). Independente da escolha adotada por cada autor (se a base de corpo ou a base de manequim técnico), observa-se que a lógica da aplicação desse fundamento está diretamente atrelada à adequada escolha da proporção formal dessa estrutura.
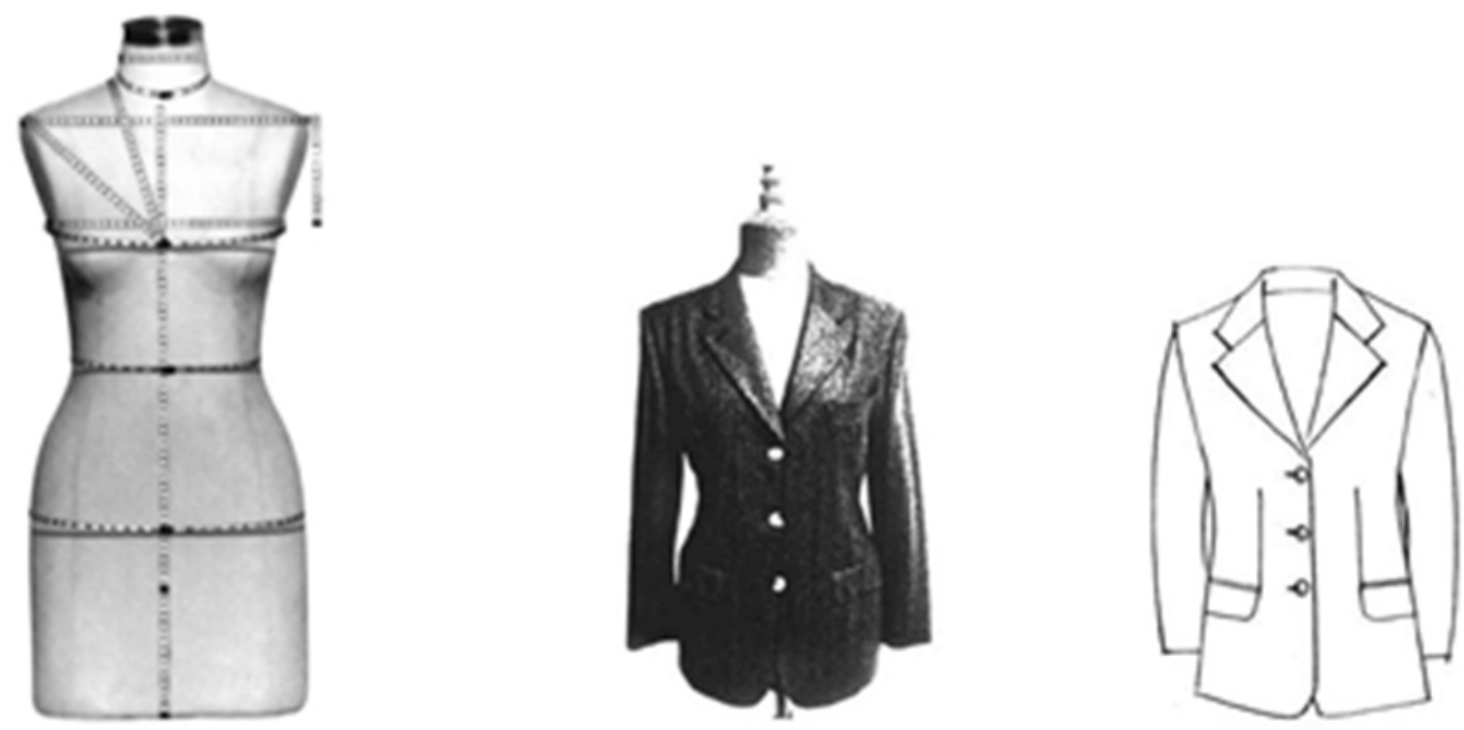

Figura 4- Manequim técnico como base

Fonte: Leite e Velloso (2004, p. 15); Tain (1998, p. 89); Lafuente (2005, p. 82)

b) A aplicação do esboço no desenho técnico do vestuário:

O desenho técnico do vestuário por meio de esboço ainda é uma questão pouco mencionada didaticamente pelos autores. Apenas Tain (1998) apresenta a importância do desenvolvimento do esboço técnico antes da configuração final do desenho (Figura 5). 

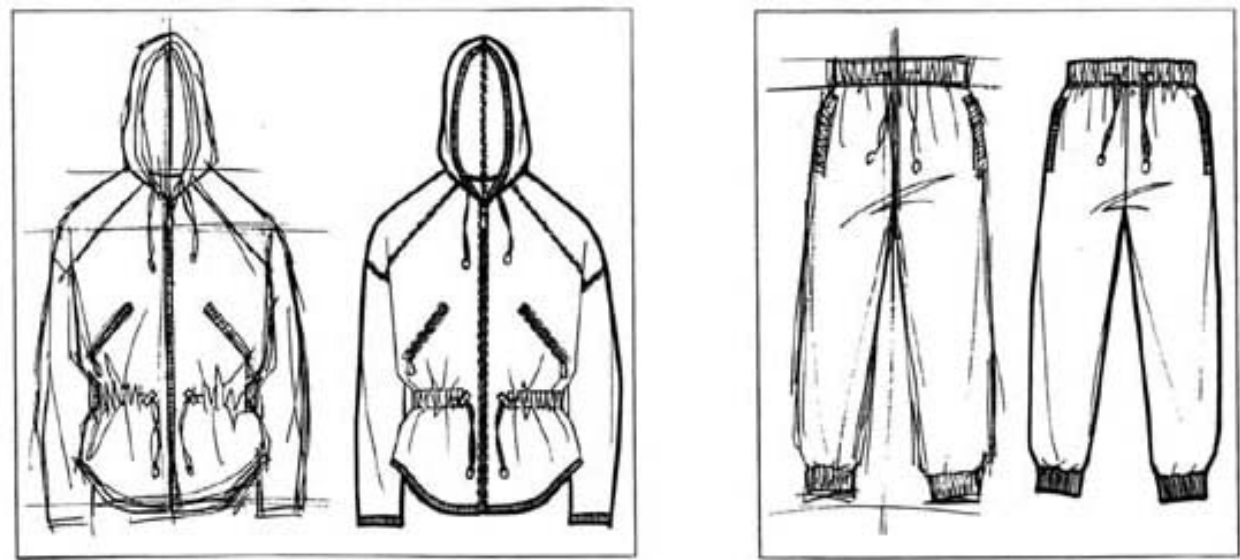

Figura 5- Aplicação do esboço na representação do desenho técnico Fonte: Tain (1998, p. 102)

Apesar disso, é possível observar nos resultados gráficos de alguns autores vestígios quanto à tendência na configuração do desenho técnico do vestuário com essa técnica. Os exemplos dos trabalhos de Shimura (2002) e Lafuente (2005) são os que mais expressam o uso do esboço e demonstram tendência em apresentar alternativas mais rápidas que contribuam no aprimoramento do aprendizado para atender com mais eficiência as necessidades práticas de mercado quanto à representação do desenho técnico do vestuário no processo de desenvolvimento de produtos (Figura 6).
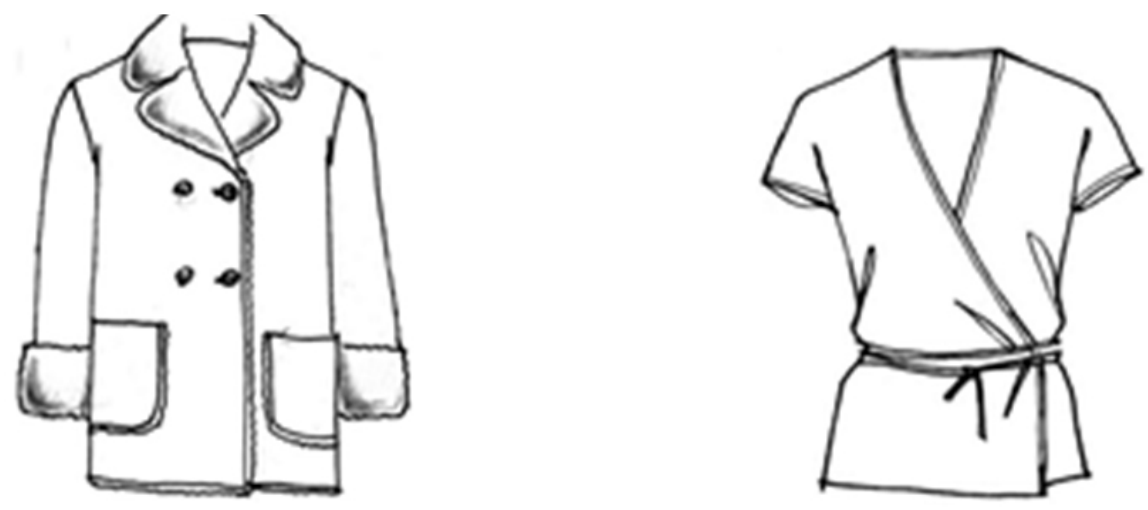

Figura 6- Desenhos técnicos com a técnica de esboço Fonte: Shimura (2002, p. 72); Lafuente (2005, p. 97)

c) A contextualização visual do desenho técnico do vestuário:

Grande controvérsia sobre a representação do desenho técnico do vestuário está relacionada no que se refere à sua adequada contextualização visual. Pela definição de que o desenho técnico do vestuário é a representação do modelo como se estivesse esticado sobre superfície plana, poder-se-ia considerar que os aspectos apresentados pelo método de Leite e Velloso (2004) seriam os mais indicados na construção do desenho técnico do vestuário.

Verifica-se que a construção da posição perfil é dada, na maior parte das vezes, a partir da projeção do diagrama da posição frente. Abling (1995), Drudi e Paci (2001), Shimura (2002) e Leite e Velloso (2004) são alguns dos autores que utilizam desse procedimento ao configurarem os seus desenhos (Figura 7). 


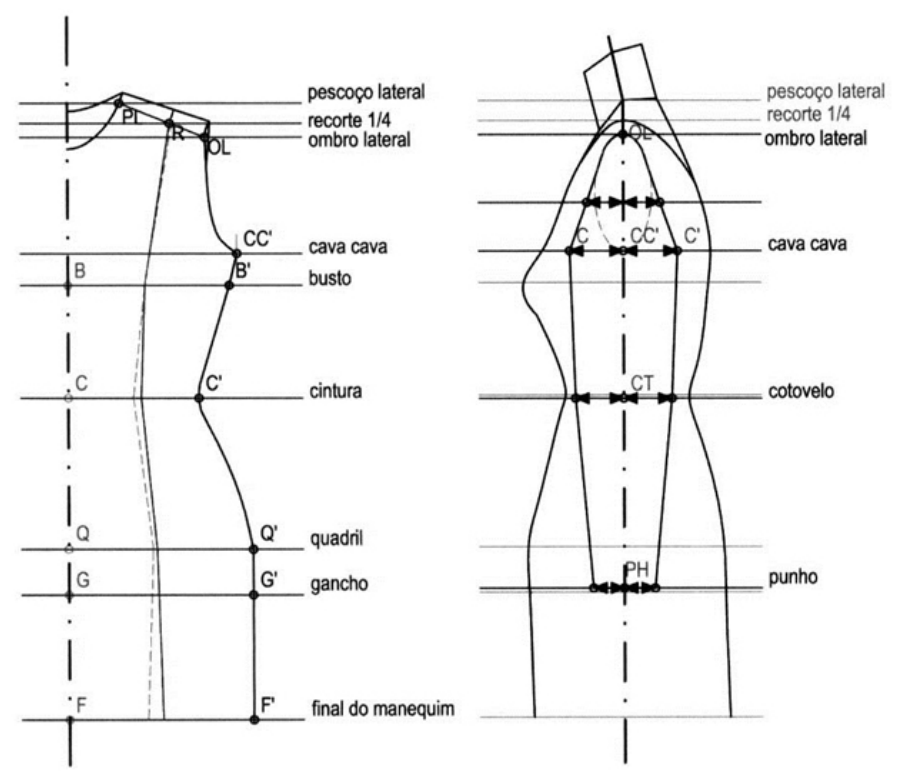

Figura 7- Construção da posição perfil a partir da projeção da posição frente Fonte: Leite e Velloso (2004, p. 33, 37).

Uma curiosidade que se observa na construção do desenho técnico do vestuário na posição perfil, é que a sua representação configura como resultado a visualização da peça como se estivesse assentada no corpo. Por outro lado, nas posições frente e costas os resultados podem apresentar tanto desenhos nessa ótica, como também em outra, já que o modelo pode também ser visualizado como se estivesse esticado sobre superfície plana.

Um exemplo disso é apresentado no caso do desenho técnico de uma jaqueta, construído pelo método de Leite e Velloso (2004), em que é possível perceber a representação do vestuário esticado sobre superfície plana nas posições frente e costas, e sobreposto em uma base de corpo ou manequim técnico na posição perfil (Figura 8).
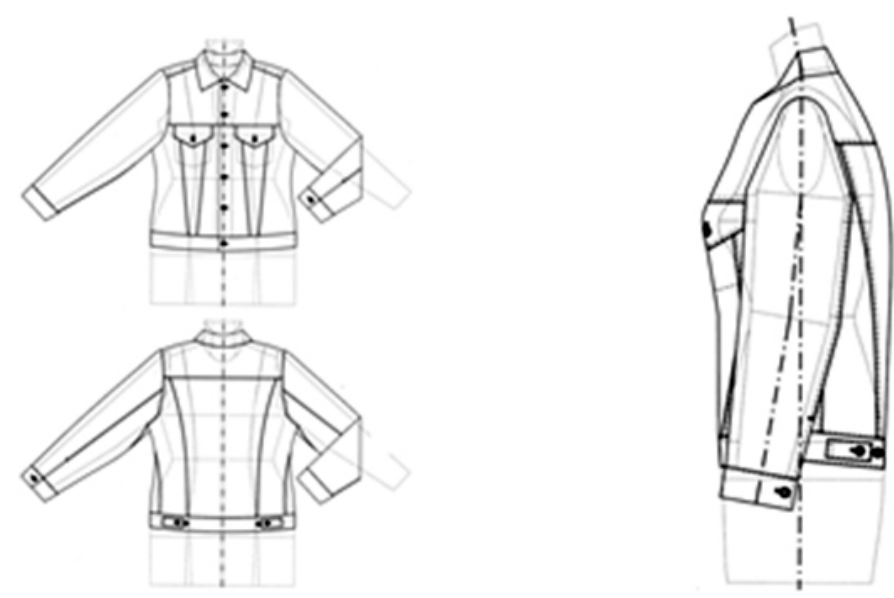

Figura 8- Visualização do desenho técnico da jaqueta

Fonte: Leite e Velloso (2004, p. 137)

Outra situação que demonstra a aplicação desse raciocínio é o desenho técnico da calça, onde a representação do gancho apresenta o traçado da curva como uma sobra de tecido dobrada para a lateral, com o conceito de peça representada esticada sobre superfície plana (Figura 9). A utilização desse princípio proporciona que elementos como costuras laterais

Projética Revista Científica de Design I Universidade Estadual de Londrina I V.2 I N.2 I Dezembro 2011 
fiquem totalmente visíveis em todas as posições representadas no desenho.
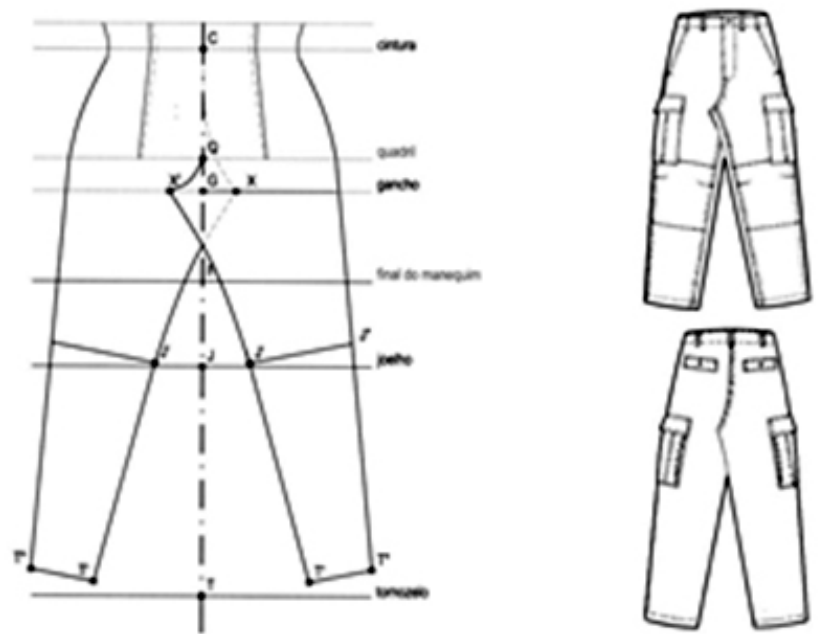

Figura 9- Visualização do gancho da calça

Fonte: Leite e Velloso (2004, p. 31); Jones (2005, p. 94)

Contudo, da mesma forma que no exemplo da jaqueta, no caso da calça a representação do vestuário na posição perfil, demonstra como resultado gráfico a peça como se estivesse apoiada sobre um suporte - corpo ou manequim técnico (Figura 10). Assim, o desenho configurado na posição perfil contextualiza uma realidade diferente daquela apresentada na representação das posições frente e costas, com conceitos de construção diferenciados para o desenvolvimento desse desenho técnico.
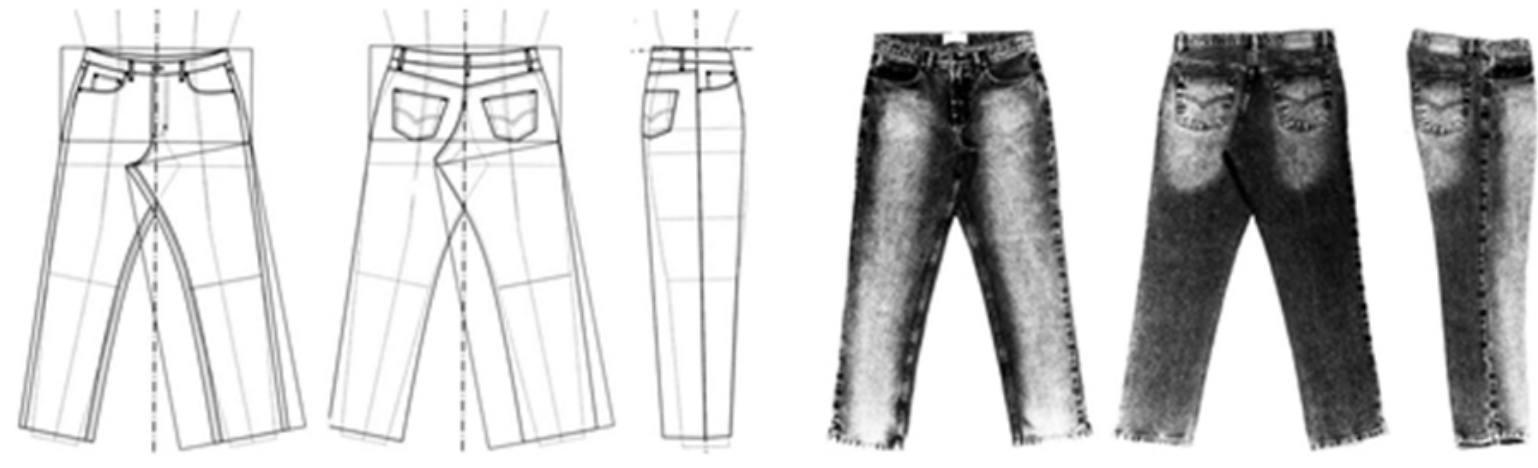

Figura 10- Visualização das posições frente e costas da calça Fonte: Leite e Velloso (2004, p. 138-139, 153)

Quanto a essa questão, Leite e Velloso (2004, p. 152) fazem importante consideração no que se refere aos resultados gerados na utilização de seu método e afirmam que: [...] jamais haverá uma correspondência absoluta, pois os desenhos são representações simétricas e bidimensionais, enquanto as roupas são tridimensionais, ou seja, têm volume.

A partir disso, observa-se que autores como Beltrame (1990), Takamura (1993), Abling (1995), Tain (1998), Drudi e Paci (2001), Shimura (2002) e Lafuente (2005) adotam como princípio norteador na representação e na visualização do desenho técnico do vestuário, a característica de sempre construir graficamente o modelo como se estivesse assentado no corpo em todas as suas posições (Figura 11).

Projética Revista Científica de Design I Universidade Estadual de Londrina I V.2 I N.2 I Dezembro 2011 


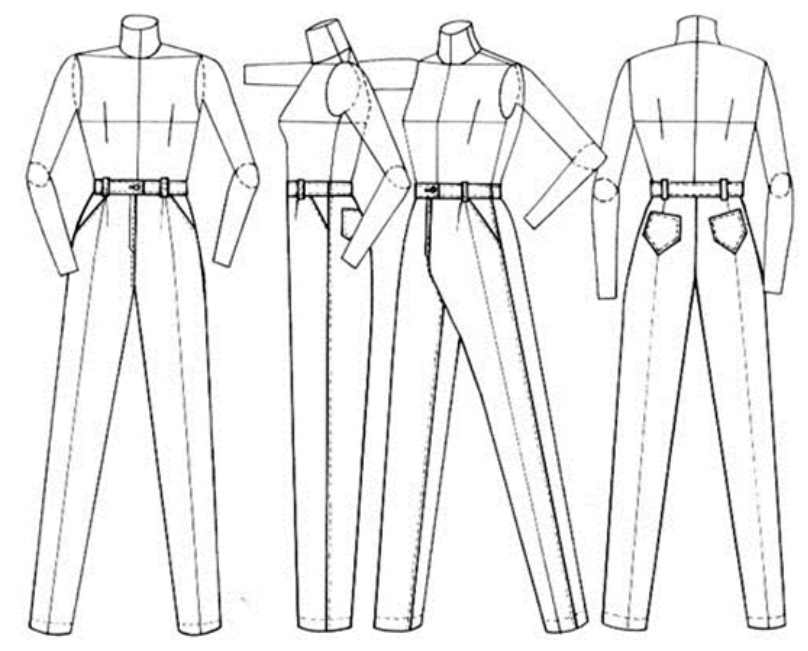

Figura 11- Posições frente, perfil, meio-perfil e costas para o desenho técnico Fonte: Drudi e Paci (2001, p. 169)

d) A aplicação do movimento no desenho técnico do vestuário:

Existem situações em que alguns autores consideram importante a articulação de movimentos nos membros (braços e pernas) e em determinadas partes da base para melhor representar o desenho técnico do vestuário. Abling (1995) e Tain (1998) utilizam esse recurso ao apresentar desenhos com os braços abertos, observando que algumas particularidades das mangas do vestuário são melhores representadas nessa posição (Figura 12). Beltrame (1990), Takamura (1993), Drudi e Paci (2001), Shimura (2002), Leite e Velloso (2004) e Jones (2005) são outros autores que também utilizam muito esse artifício em seus trabalhos durante a representação do desenho técnico do vestuário.
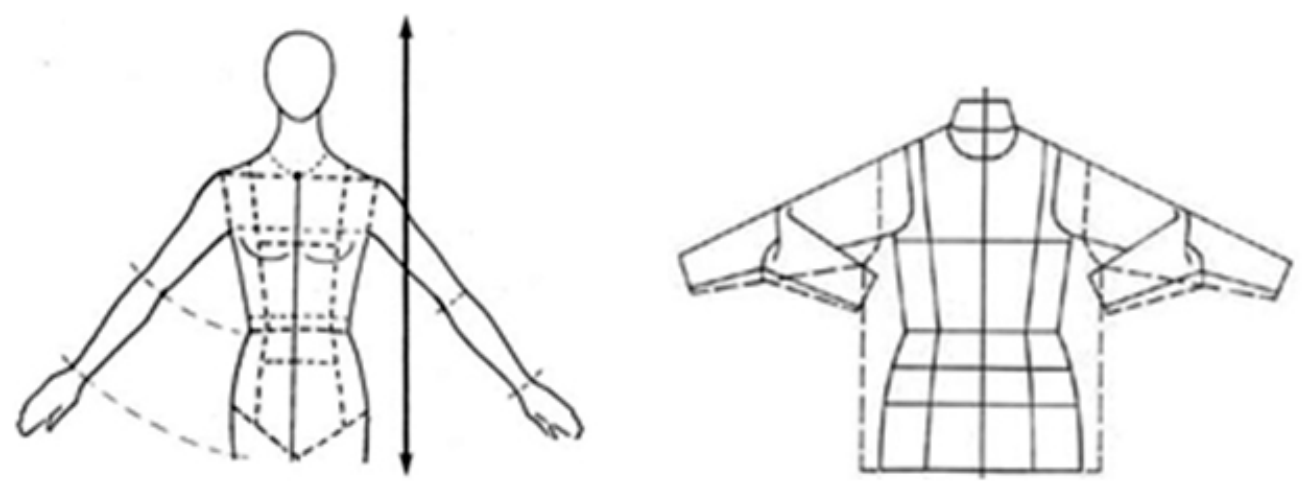

Figura 12- Aplicação de movimento na base Fonte: Abling (1995, p. 165); Tain (1998, p. 91)

Quanto ao desenho técnico do vestuário em movimento, Jones (2005) apresenta um exemplo bastante interessante, que ela denomina como desenho plano animado. Esse desenho constitui-se de uma representação do vestuário que traz mangas articuladas que expressam as linhas de dobras do tecido (Figura 13). Segundo a autora, o uso desse recurso proporciona mais dinâmica no resultado final da representação gráfica da peça.

Apesar de ser um recurso diferenciado, é importante lembrar que artifícios muito exagerados aplicados na representação do desenho técnico do vestuário podem comprometer os principais objetivos comunicativos dessa ferramenta no processo de desenvolvimento de produtos. 


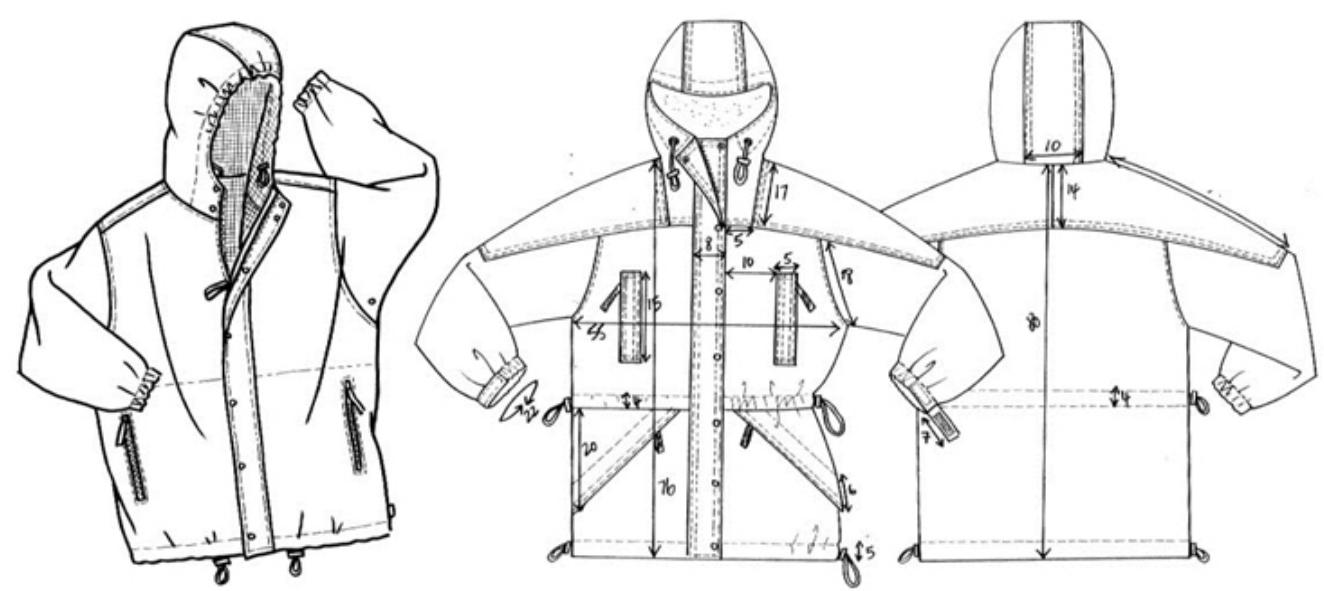

Figura 13 - Desenho plano animado e o desenho técnico do vestuário

Fonte: Jones (2005, p. 94)

e) A representação do caimento no desenho técnico do vestuário:

Conforme citado por Araújo (1996), os modelistas são os intérpretes dos modelos criados pelos designers. Além dos aspectos técnicos do vestuário, uma importante informação que auxilia o profissional da área de modelagem para fazer a interpretação do desenho concebido pelo designer é a demonstração do caimento da matéria-prima têxtil em função do modelo.

Normalmente, o caimento do tecido é uma informação que dificilmente pode ser representada graficamente caso se considere o vestuário esticado sobre superfície plana. Percebe-se, então, que a representação técnica do caimento da peça só é possível nos casos em que se considera o vestuário apoiado sobre a base de corpo ou de manequim técnico.

Todos os autores concordam quanto à importância da representação do caimento no desenho técnico do vestuário. Mesmo aqueles que trabalham com conceitos e fundamentos para construção do desenho técnico do vestuário como produto esticado sobre superfície plana, afirmam que em situações em que há a existência de elementos como pregas, franzidos, babados, drapeados e outros tipos de detalhes mais específicos, torna-se necessário o uso de recursos gráficos que demonstrem as dobras e a volumetria da matéria-prima têxtil (Figura 14). É provável que a aplicação desses critérios apontados pelos autores, tenha como principal meta a busca de meios que facilitem o profissional da área de modelagem a interpretar melhor os aspectos de vestibilidade do traje.
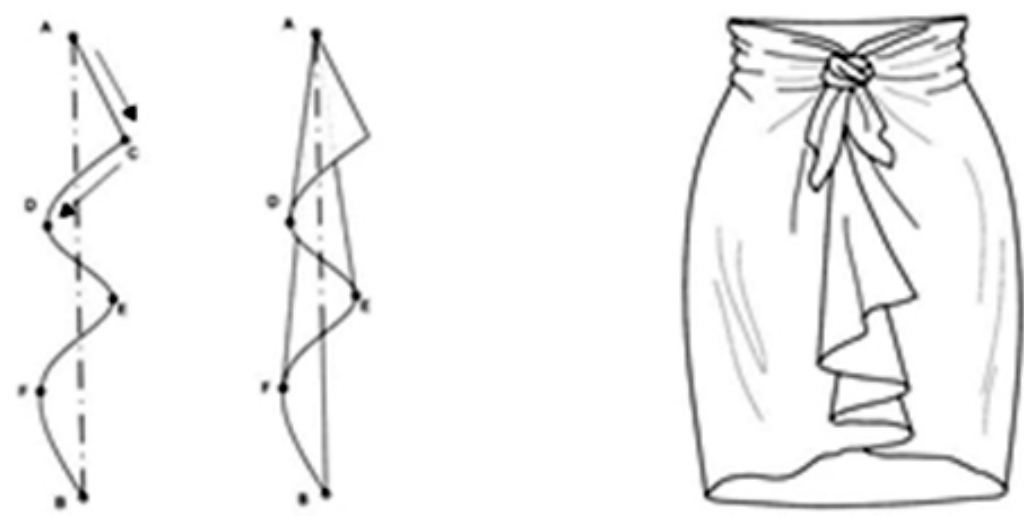

Figura 14- Representação de caimento da matéria-prima 
O desenho técnico do vestuário sob a ótica do modelista

Fonte: Leite e Velloso (2004, p. 94, 97, 118)

f) O detalhamento do desenho técnico do vestuário:

Na maior parte dos casos, o designer estabelece a representação dos detalhes da peça de vestuário apenas na parte externa do modelo. Entretanto, há situações em que é necessário representar detalhes de acabamento interno que são fundamentais para o entendimento de procedimentos técnicos de montagem e execução, que devem ser aplicados na confecção do vestuário. É importante que esses detalhes sejam apresentados ao modelista já nas primeiras etapas de modelagem da peça.

Em relação aos métodos pesquisados, percebe-se que essa questão é pouco trabalhada na construção do desenho técnico do vestuário. De todos os autores citados apenas Takamura (1993), Tain (1998) e Leite e Velloso (2004) apontam algumas observações nesse sentido.

Takamura (1993) e Tain (1998) apresentam alguns exemplos de desenhos que procuram demonstrar a representação do avesso da peça em um contexto geral no desenho (Figura 15). Já Leite e Velloso (2004) fazem apontamentos mais significativos em que esclarecem melhor as informações dos detalhes de acabamento do vestuário por meio de desenhos ampliados, com a articulação dos mesmos em situações abertas e fechadas simultaneamente (Figura 16).
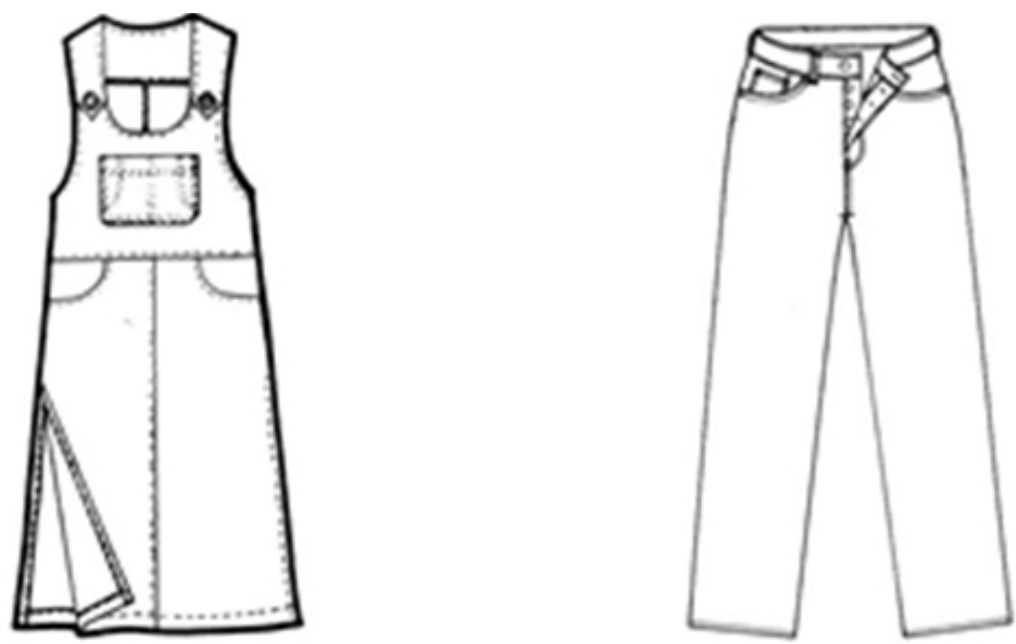

Figura 15- Representação de detalhe do avesso da peça Fonte: Tain (1998, p. 98); Takamura (1993, p. 76)
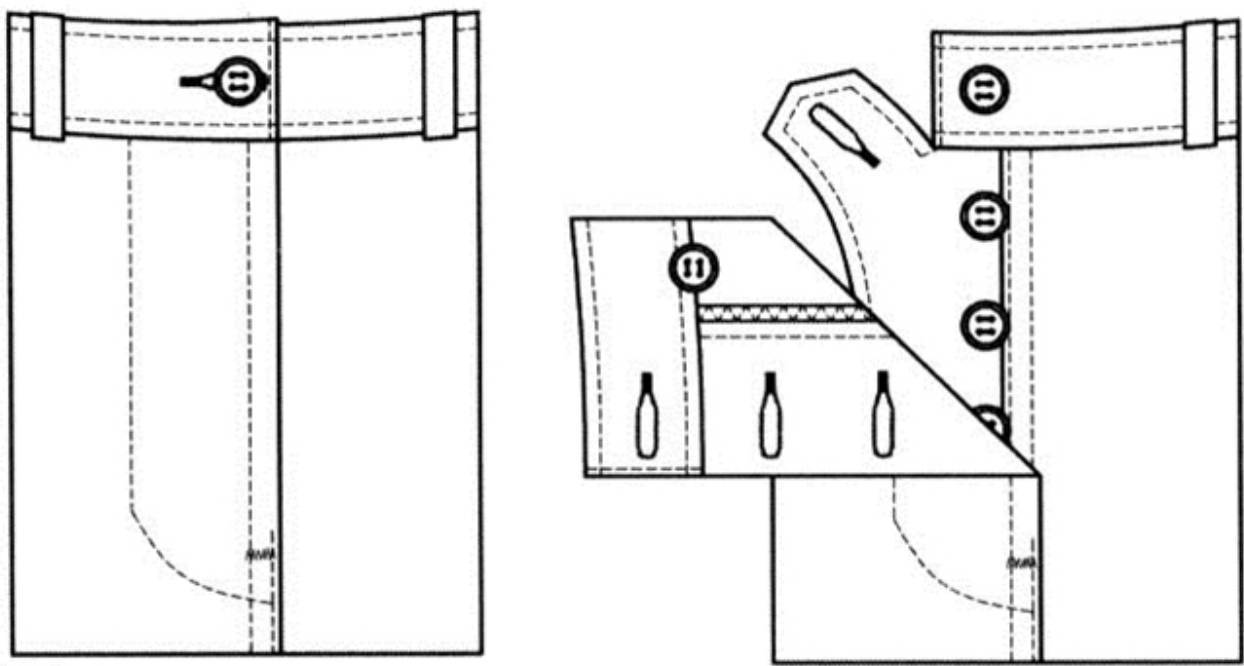

Figura 16- Representação de detalhe externo e interno 
Fonte: Leite e Velloso (2004, p. 121)

Essas considerações demonstram que as informações para uma boa comunicação por meio do desenho técnico do vestuário vão além da mera construção de um desenho geral do modelo. No que diz respeito à representação de detalhes, deve-se procurar utilizar linguagem condizente para construção dos elementos, com o intuito de atender as necessidades de comunicação entre designer e modelista e também dos profissionais da área de produção.

Todo esse panorama revela o alto grau de complexidade que existe na questão da representação do desenho técnico do vestuário. Mesmo nos métodos e nas considerações dos vários autores, existem controvérsias que precisam ser analisadas com bastante cuidado. Buscar caminhos que orientem melhor as diretrizes desse campo por meio da ciência é de extrema necessidade, uma vez que as instituições de ensino de moda têm sob sua responsabilidade a adequada formação do profissional que irá ingressar nas indústrias de confecção.

\section{Procedimentos metodológicos}

Segundo Gil (2006), a pesquisa pode ser definida como o procedimento racional e sistemático que tem como objetivo proporcionar respostas aos problemas. Uma vez que o presente estudo tem como objetivo verificar a validade dos princípios e fundamentos existentes para a construção do desenho técnico do vestuário junto aos profissionais da área de modelagem, atuantes nas instituições de ensino e nas indústrias de confecção, o tipo de pesquisa definido para orientar essa investigação caracteriza-se como sendo descritiva.

Essa escolha é dada em função do fenômeno apresentar-se como uma situação específica existente em determinado grupo - no caso, os profissionais da área de modelagem. A obtenção de dados descritos pelos próprios agentes participantes (modelistas), proporciona um levantamento de opiniões direcionado para o fenômeno existente em que envolve a comunicação entre designer e modelista por meio do desenho técnico do vestuário nos projetos da área de moda.

Ainda no que se refere à abordagem do problema, a pesquisa também é classificada como sendo qualitativa. A escolha pela pesquisa qualitativa torna-se importante nesse contexto, uma vez que a sua inserção preocupa-se em observar a complexidade do comportamento humano do grupo estudado quanto aos aspectos relacionados na interpretação do desenho.

Para efetuar o levantamento das informações junto aos agentes participantes da pesquisa, definiu-se a escolha da entrevista como instrumento de coleta de dados, já que ela é considerada uma das técnicas que possibilita a obtenção de dados acerca do comportamento humano. Sua aplicação nesse estudo está embasada no fato dela oferecer determinado grau de flexibilidade em que permite ao entrevistador esclarecer o significado das perguntas às pessoas entrevistadas para preservar, na medida do possível, o conteúdo qualitativo das respostas indicadas.

A organização dessa entrevista se deu a partir de um roteiro com perguntas predeterminadas e de quadros ilustrativos com conceitos e elementos gráficos utilizados nos métodos de construção do desenho técnico do vestuário dos autores citados.

O trabalho de campo se inseriu tanto no ambiente acadêmico como no industrial, tendo em vista que o problema no processo de comunicação entre designer e modelista por meio do desenho técnico do vestuário se faz presente em ambas as situações. Geograficamente, foram selecionadas as cidades de Londrina e Maringá, municípios localizados na região Norte do Paraná, considerado grande pólo do setor do vestuário. 
O desenho técnico do vestuário sob a ótica do modelista

A escolha dos profissionais da área de modelagem como agentes participantes, baseiase no pressuposto de que eles são os principais receptores da informação gráfica do desenho técnico do vestuário desenvolvido pelo designer, sendo responsáveis pela materialização formal do produto. No âmbito acadêmico foram selecionadas cinco docentes responsáveis pela disciplina da área de modelagem dos cursos superiores de moda (Grupo A) e no contexto industrial foram escolhidas mais quatro profissionais da área de modelagem (Grupo B).

Uma vez que o tipo de pesquisa é caracterizado com sendo descritiva e qualitativa, a comparação dos dados se dará de forma indutiva, com base nas respostas dos entrevistados. A comparação das informações descritas pelos agentes participantes apresentará as impressões de cada um, direcionando assim alguns parâmetros para serem discutidos posteriormente. Basicamente, a estruturação da pesquisa se organiza da seguinte maneira: 


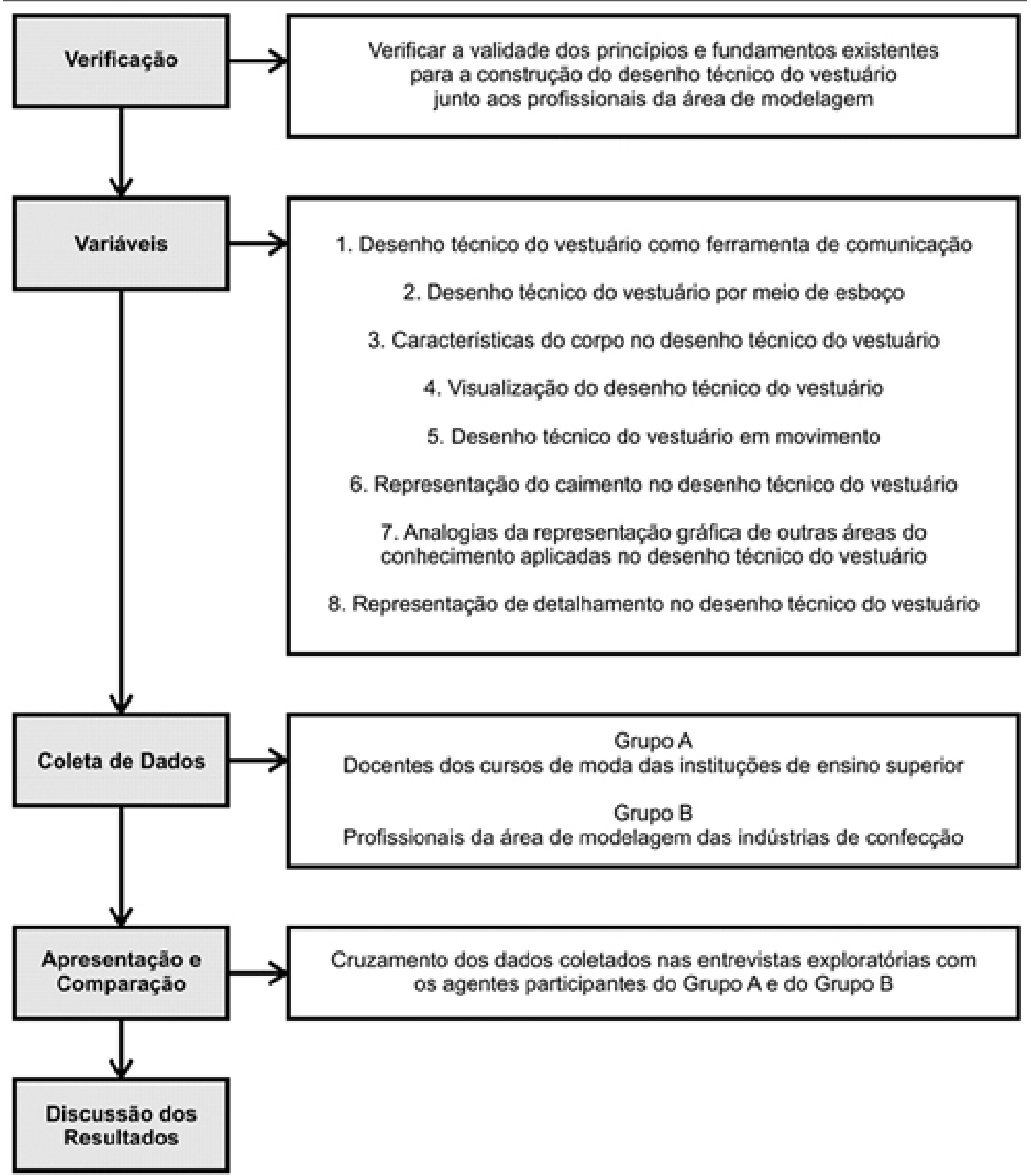

Figura 17- Estruturação da pesquisa Fonte: Própria

\section{Apresentação e discussão dos resultados}

Após a aplicação da entrevista, de caráter exploratório, foi feito o cruzamento das opiniões dadas pelos grupos selecionados para cada variável adotada. Na sequência são apresentados os aspectos mais significativos para discussão dessa pesquisa.

1) Quanto ao desenho técnico do vestuário como ferramenta de comunicação: Sobre o papel do desenho técnico do vestuário durante o desenvolvimento de produtos de moda, docentes e profissionais da área de modelagem afirmam que sua principal função é a transmissão das informações relativas ao produto a ser materializado, o que corresponde 
O desenho técnico do vestuário sob a ótica do modelista

aos pensamentos de Ferreira (2006), que afirma que o desenho torna-se uma anotação comunicativa com função afirmativa; e de Berenguer e Pastor (2004), que consideram o desenho com ferramenta funcional de conhecimento.

Apesar da problemática na leitura e na interpretação do desenho por parte do modelista, a maioria das entrevistadas afirmou não ter essa dificuldade ao ressaltar que conhecimentos específicos de modelagem aliados às noções de costura permitem que elas consigam interpretar as informações gráficas atribuídas ao modelo. Entre as nove entrevistadas na pesquisa, somente duas agentes do Grupo A (docentes) revelaram que o desenho no qual tem contato não transmite informações suficientes para o desenvolvimento da modelagem da peça.

Por outro lado, mesmo considerando não possuírem dificuldades na interpretação do desenho, algumas pessoas apontaram que em alguns casos, o molde da roupa acaba ficando diferente da idéia pensada pelo designer. É o caso das opiniões de duas agentes do Grupo A e de uma agente do Grupo B (modelistas), que mesmo afirmando não possuir dificuldades em ler e interpretar os desenhos, apontaram possibilidades da modelagem não ficar de acordo com o que foi pensado pelo designer.

Ainda no que se refere quanto ao aspecto do desenho como ferramenta de comunicação, o retorno do processo ao designer ou estilista foi apontado como ponto unânime entre as entrevistadas quando questionadas sobre a falta de entendimento das informações gráficas contidas no desenho técnico do vestuário. Tal comportamento revela cuidado por parte das profissionais da área de modelagem para buscar informações mais corretas para o desenvolvimento de suas tarefas, mas ao mesmo tempo demonstra prejuízo de tempo no processo de desenvolvimento de produtos.

Sobre a qualidade gráfica do desenho técnico do vestuário, a maioria considerou como sendo de bom padrão. Contudo, é importante ressaltar que essas pessoas deram suas opiniões embasadas no trabalho de profissionais e de alunos com o qual tem contato já há algum tempo dentro das indústrias ou das instituições de ensino. Na verdade, não há um consenso equilibrado entre as entrevistadas sobre essa questão, pois algumas consideraram que a qualidade do desenho ainda deixa muito a desejar, ficando abaixo da média.

2) Quanto ao desenho técnico do vestuário por meio de esboço:

As agentes participantes do Grupo B (modelistas) não fizeram nenhuma restrição quanto à utilização do esboço no desenvolvimento do desenho técnico do vestuário e revelaram ser possível interpretar o modelo por meio dessa técnica. Em contrapartida, as agentes do Grupo A (docentes), apesar de concordarem ser possível fazer a leitura e a interpretação do modelo por meio do esboço, fizeram algumas observações quanto a essa questão.

No caso dos exemplos de Tain (1998), Shimura (2002) e Lafuente (2005) utilizados na entrevista, três docentes consideraram que existem problemas de proporção na representação dos desenhos, com algumas informações de elementos e detalhes da peça que ficam subentendidas. Em função desse fato, uma das entrevistadas especifica que o esboço não é o ideal para a construção do desenho técnico do vestuário. Além disso, uma outra agente do mesmo grupo reforça que da forma como o desenho técnico é feito atualmente pelos designers, torna-se perigoso propor que o mesmo seja feito dessa maneira e afirma ser arriscado a adoção da técnica do esboço pelos profissionais pela falta de maturidade.

No entanto, todas as agentes do Grupo A concordaram em dizer que desde que o desenho técnico do vestuário por meio de esboço seja feito de forma adequada, com informações necessárias para o desenvolvimento da modelagem, a sua aplicação poderia ser viável e contribuiria significativamente no rendimento do processo.

3) Quanto às características do corpo no desenho técnico do vestuário: 


\section{Celso Tetsuro Suono}

Considerar as características do corpo na representação do desenho técnico do vestuário é ponto comum entre todas as entrevistadas, já que em muitos casos as proporções do vestuário são melhores interpretadas a partir desses aspectos. Observa-se então, a importância das considerações de Castilho (2004), quando afirma que a estrutura do corpo integrada ao vestuário torna-se o suporte ideal para a moda.

Por outro lado, nas situações em que o produto passa a ser exportado para o mercado externo, em que os biótipos dos corpos têm padrões físicos diferenciados em relação ao nosso mercado, as agentes dos dois grupos apontaram não ser necessário o desenvolvimento de um novo desenho técnico. Para todas as entrevistadas, a utilização de uma tabela de medidas que repasse os dados para a alteração do molde de acordo com as dimensões longitudinais (alturas e comprimentos) e proporções corporais (circunferências) das etnias de cada região já é suficiente para as eventuais adaptações de modelagem.

Vale ressaltar ainda que nos casos em que o produto é desenvolvido para corpos fora de parâmetros físicos normais, a questão quanto à representação gráfica do desenho técnico abriu espaço para novas reflexões sobre o assunto. Ao mesmo tempo em que algumas entrevistadas afirmaram que o desenho técnico deveria ser representado levando em conta os desvios da estrutura física, outras apontaram esse aspecto como fator facultativo e consideraram que informações descritivas poderiam acompanhar o desenho do vestuário construído de forma normal.

Sobre essa questão é interessante destacar a opinião de uma das agentes do Grupo A (docentes), em que aponta que o desenho técnico representado sobre um corpo com desvios físicos poderia causar um choque negativo às pessoas, pois provocaria desconforto ao ser visualizado. Ainda nesse sentido, outra agente do mesmo grupo também considera que o desenho deva ser representado de forma natural, sendo função do modelista camuflar as eventuais características físicas do corpo durante o desenvolvimento da modelagem.

4) Quanto à visualização do desenho técnico do vestuário:

De todas as variáveis da pesquisa, talvez a visualização do desenho técnico do vestuário seja a que mais gera controvérsias entre os autores citados na Revisão de Literatura e as entrevistadas desse estudo. Percebe-se isso tanto nas respostas dadas pelas agentes participantes do Grupo A (docentes) como do Grupo B (modelistas).

No Grupo A, duas agentes apontaram como sendo de sua preferência a visualização do desenho técnico do vestuário representado esticado sobre superfície plana e outras duas agentes destacaram ser melhor observar o desenho da roupa como se estivesse assentado sobre o corpo. Apenas uma agente desse grupo afirmou que de acordo com sua experiência profissional, sempre visualizou o desenho técnico de forma chapada, não tendo contato com o desenho pela outra ótica, ou seja, vestido no corpo. Em relação ao Grupo B, aconteceu a mesma divisão de opiniões semelhante ao Grupo A.

Contudo, observou-se um fato curioso a ser apontado sobre as respostas dadas por duas agentes do Grupo A. Quando indagadas sobre qual o melhor exemplo para a visualização do desenho técnico, após a apresentação de um quadro ilustrativo com exemplos gráficos, ambas entraram em contradição com as opiniões dadas na entervista, deixando transparecer certa instabilidade sobre seus pontos de vista em relação a esse assunto.

Ainda nesse sentido, a representação de elementos como gancho da calça e cava da manga, que possuem propriedades e configurações relativas ao contorno anatômico do corpo, também divide as opiniões das entrevistadas. Para algumas, a representação da entrada de gancho virada e da cava sobre a manga no desenho técnico auxilia na interpretação do modelo. Em contrapartida, outras pessoas consideram que essa informação só teria fundamento se houvessem dimensões especificadas desses elementos para a sua modelagem. Uma agente do

Projética Revista Científica de Design I Universidade Estadual de Londrina I V.2 I N.2 I Dezembro 2011 
O desenho técnico do vestuário sob a ótica do modelista

Grupo A observa que normalmente tais elementos costumam constar em tabela de medidas e essas informações acabam sendo de conhecimento dos profissionais da área de modelagem. Por outro lado, a maioria das entrevistadas entra em comum acordo no que se refere às posições que devem ser representadas no desenho técnico do vestuário para a interpretação do modelo, quando consideram ser essencial a visualização das vistas frente, costas e perfil/ lateral.

5) Quanto ao desenho técnico do vestuário em movimento:

Sobre a representação do vestuário em movimento, a maioria das entrevistadas apontou esse fato como não sendo ideal para a representação do desenho técnico na área de moda.

Contudo, duas agentes do Grupo A (docentes) e uma agente do Grupo B (modelistas) afirmaram ser possível a utilização desse desenho. Ainda nesse sentido, uma outra agente do Grupo A observou que o desenho do vestuário em movimento, se bem representado graficamente, poderia ser considerado uma boa forma de apresentar as informações para o desenvolvimento da modelagem da peça. Essa afirmação vai de encontro com as recomendações dadas pelos autores Abling (1995), Tain (1998), Beltrame (1990), Takamura (1993), Drudi e Paci (2001), Shimura (2002), Leite e Velloso (2004) e Jones (2005).

Entretanto, duas agentes do Grupo B justificam o desenho em movimento como uma representação inadequada para o desenho técnico do vestuário em função dele ocultar partes importantes da peça. Uma outra agente do mesmo grupo reforça essas considerações e observa que esse tipo de desenho gera dificuldades na interpretação para a construção do molde.

Por outro lado, uma agente do Grupo A salienta que a representação do desenho do vestuário em movimento não deve ser descartada totalmente, uma vez que pode haver casos dele ser oportuno para a construção gráfica de roupas com características mais complexas. Para outra agente desse grupo, o desenho técnico em movimento oferece possibilidades de perceber melhor os aspectos de volumetria da peça, com condições de visualizar elementos que não seriam contemplados no desenho em posição estática.

Vale ainda lembrar que para algumas entrevistadas dos dois grupos, a representação do desenho técnico do vestuário tanto na posição estática como em movimento torna-se indiferente, já que afirmam conseguir interpretar as informações gráficas da peça para o desenvolvimento da modelagem em qualquer uma das situações.

6) Quanto à representação do caimento no desenho técnico do vestuário:

A maioria das entrevistadas identifica o caimento da matéria-prima têxtil no desenho técnico do vestuário pela representação de dobras e ondulações que assumem aspectos formais em função das características físicas do tecido, que segundo Grave (2004) trabalham em sentidos verticais e horizontais de direção sob a ação de movimento.

Para quatro agentes do Grupo A (docentes) e três agentes do Grupo B (modelistas), a representação do caimento do tecido torna-se aspecto importante que deve ser contemplado no desenho técnico do vestuário. Em contrapartida, uma agente do Grupo B considera não ser importante a aplicação desse recurso no desenho e afirma que isso em nada contribui na interpretação do modelo.

Na concepção de uma agente do Grupo A, interpretar corretamente a informação do caimento só seria possível se a matéria-prima têxtil fosse especificada de forma descritiva. De acordo com a entrevistada, a representação do caimento no desenho de moda deve estar presente no desenho de estilo e não no desenho técnico. Ela ressalta que o desenho de contexto artístico complementa as informações do desenho técnico e justifica a sua existência no aprendizado dos cursos de moda nas instituições de ensino.

Outra observação importante dada por duas agentes do Grupo A como proposta para

Projética Revista Científica de Design I Universidade Estadual de Londrina I V.2 I N.2 I Dezembro 2011 
a questão da representação do caimento no desenho técnico considera que o vestuário deva ser representado de forma esticada, aberta ou chapada em um dos lados, e de maneira como se estivesse assentado no corpo do outro, com a exposição da fluidez e da densidade do tecido. As agentes exemplificaram a representação da saia godê para ilustrar essa hipótese, mas admitiram que para determinados tipos de estruturas, tal recurso poderia não funcionar e trazer mais complicações na representação do desenho técnico.

7) Quanto às analogias da representação gráfica de outras áreas do conhecimento aplicadas no desenho técnico do vestuário:

Ao serem indagadas sobre a teoria projetiva, a maioria das entrevistadas respondeu não conhecer esse campo da representação gráfica. Apenas uma agente do Grupo A (docentes) respondeu ter tido contato com os seus fundamentos, uma vez que a mesma possui formação na área de Arquitetura. Ela ressaltou a importância desses conhecimentos serem utilizados na construção do desenho técnico do vestuário e considerou a possibilidade deles auxiliarem significativamente o trabalho dos modelistas. Também afirmou que a partir dos princípios da teoria projetiva, desenhos em perspectiva poderiam ser feitos para a representação gráfica do desenho técnico na área de moda.

Entretanto, mesmo sem conhecimentos sobre teoria projetiva, foi possível perceber que todas as entrevistadas costumam, de algum modo, aplicar ou absorver tais conceitos intuitivamente no desempenho de suas atividades durante a modelagem das peças de vestuário.

Prova disso, é a opinião unânime das agentes dos dois grupos quando consideram a importância da proporção e da aplicação da escala métrica na construção do desenho técnico. Todas as entrevistadas enfatizam que o uso da escala métrica facilita consideravelmente a interpretação do desenho e proporciona uma leitura mais correta das proporções das partes que constituem o modelo.

Mesmo nos casos em que não há a aplicação da escala métrica por parte do designer para desenvolver o desenho da roupa, as entrevistadas apontaram que o cânone de proporção do corpo humano poderia servir como parâmetro referencial de escala para a adequada representação da proporção do vestuário. Contudo, uma agente do Grupo A faz uma pequena ressalva nesse sentido, pois atribui ser necessária a construção correta do cânone da figura humana em escala métrica, com as devidas proporções anatômicas, caso contrário o resultado final do desenho técnico seria comprometido. Essa consideração vai de encontro com o fenômeno apresentado por Tain (1998), quando compara os resultados de dois exemplos de desenhos feitos a partir de estruturas de bases de corpos com proporções diferentes.

Outro ponto importante diz respeito à diferenciação do traçado dos pesos das linhas que configuram o desenho técnico, apontado por Ching (2000) e Giesecke et al (2002) como fundamental para a boa leitura do desenho técnico. Mesmo não sendo uma opinião comum entre todos os profissionais da área de modelagem, a maioria das entrevistadas apontou que a diferenciação das espessuras dos traços que conformam o desenho facilita a interpretação da roupa durante o desenvolvimento de seu molde. Entre os dois grupos, 1/3 do universo pesquisado afirmou ser facultativo a representação diferenciada das espessuras das linhas no desenho técnico do vestuário. Vale lembrar que a falta de conhecimentos sobre os fundamentos da teoria projetiva por parte dessas agentes pode ter condicionado essa opinião com relação a esse assunto.

Ainda nesse contexto, as entrevistadas apontaram que informações escritas também deveriam, na medida do possível, acompanhar as informações gráficas do desenho técnico, já que elas auxiliam na interpretação do modelo. Apesar de uma agente de cada grupo considerar a utilização de informações escritas de extrema importância, as mesmas admitiram

Projética Revista Científica de Design I Universidade Estadual de Londrina I V.2 I N.2 I Dezembro 2011 
O desenho técnico do vestuário sob a ótica do modelista

que há casos em que é necessário a marcação de dados que descrevam alguns aspectos de execução do modelo. No geral, as agentes dos dois grupos recomendaram como exemplos de informações para serem descritas os detalhes de acabamento, os aviamentos que saiam do padrão de confecção da peça e os elementos que possam gerar leitura de duplo sentido.

Outra questão quanto às analogias da representação gráfica refere-se à marcação de cotas no desenho técnico do vestuário. Sobre esse assunto, as opiniões das entrevistadas se dividem, uma vez que algumas apontam como mais prioritário a marcação de dimensões gerais e outras as medidas de detalhes da roupa. Independente disso, fato interessante a ser citado é a observação de uma agente do Grupo A, em que considera que se o desenho técnico estiver representado na sua devida proporção com escala métrica, as dimensões do modelo ficam subentendidas naturalmente, já que o modelista costuma condicionar a percepção do seu olhar conforme a sua experiência.

Além disso, outra agente do Grupo A também coloca ser de sua preferência a marcação das cotas fora do desenho, uma vez que elas possibilitam uma leitura mais clara e organizada entre as informações gráficas e as informações escritas, o que vai de encontro com as recomendações dadas por French e Vierck (2002).

8) Quanto à representação de detalhamento no desenho técnico do vestuário:

A questão do detalhamento no desenho técnico do vestuário também surgiu como proposta de investigação durante o desenvolvimento dessa pesquisa. Isso porque, ficou evidenciado que a representação de detalhes em desenhos técnicos nas outras áreas de conhecimento apresenta-se como valioso recurso utilizado pelos profissionais para a apresentação de projetos.

Sobre essa questão, tanto as entrevistadas do Grupo A (docentes) quanto do Grupo B (modelistas) apontaram ser importante a representação de detalhes junto ao desenho geral da peça. Quando indagadas sobre qual a melhor forma para representá-los, a maioria sugeriu que eles fossem desenvolvidos próximos aos desenhos, de maneira ampliada com indicações de especificações da peça.

Uma agente do Grupo B apontou que em situações em que fosse representado o detalhamento de partes internas do vestuário, os desenhos deveriam ser construídos em folhas separadas, para não gerar confusão na leitura com os detalhes externos, que estariam representados ao lado do desenho técnico geral.

Nessa linha de raciocínio, outra agente do mesmo grupo considerou que na representação de muitos detalhes da peça, tanto internos quanto externos, os mesmos poderiam ser feitos separados do desenho técnico e anexados posteriormente. Independente disso, vale ressaltar a opinião de outra agente do Grupo A, que observa ser indispensável aplicação de bom-senso durante a distribuição dos desenhos para se ter uma coerência na diagramação.

Outro fato importante na representação do detalhamento diz respeito a um quadro ilustrativo com exemplos de detalhes construídos pelo método de Leite e Velloso (2004), com elementos em situações que mostravam, simultaneamente, o aspecto externo junto ao interno ao mesmo tempo. Verificou-se que as entrevistadas dos dois grupos tiveram um entendimento claro e rápido desses desenhos e não deixaram margem para interpretações de duplo sentido. A partir daí, observa-se que a representação de detalhes no desenho técnico do vestuário deve levar em conta as eventuais necessidades de leitura do modelista, com o princípio de que é fundamental apresentar a visualização dos elementos em ambas as situações (externa e interna).

Sobre quais recomendações que poderiam ser sugeridas para a melhor representação do detalhamento no desenho técnico do vestuário que normalmente não são especificadas, as respostas das entrevistadas demonstraram uma ampla diversidade de opiniões. Percebe-se, a

Projética Revista Científica de Design I Universidade Estadual de Londrina I V.2 I N.2 I Dezembro 2011 
partir daí, que a melhor orientação a ser dada nesse sentido é que o designer procure sempre manter um diálogo direto junto ao modelista para verificar as exigências e as particularidades que cada produto possui, conforme as suas especificidades, para a construção de um adequado detalhamento.

\section{Considerações finais}

O desenho técnico do vestuário revelou nessa pesquisa o alto grau de complexidade que envolve esse assunto para o campo da moda, uma vez que as tentativas em direcionar os seus conceitos para a sua construção ainda apresentam aspectos controversos entre os vários autores e pesquisadores da área.

Por outro lado, não se deve ignorar os esforços e as sugestões existentes para a sua construção, já que muitos profissionais se familiarizaram com tais diretrizes para hoje desempenharem suas tarefas no trabalho.

A investigação junto aos profissionais da área de modelagem, tanto nas instituições de ensino como nas indústrias de confecção, comprovou que os princípios e fundamentos já existentes para a construção do desenho técnico do vestuário tornam-se válidos para ambos os casos. $O$ que se percebe é a necessidade de se repensar essas diretrizes e buscar propostas que orientem melhor o uso dessa ferramenta.

Fica evidenciado que mais do que um meio de expressão, o desenho técnico do vestuário possui, antes de tudo, a função comunicativa durante o processo, sendo uma linguagem que deve apresentar soluções afirmativas para a materialização do produto, e que deve funcionar abertamente entre as várias pessoas envolvidas nos diversos setores.

A investigação junto aos profissionais da área de modelagem apresentou parâmetros para que novas reflexões sejam feitas a respeito da aplicação mais frequente do esboço técnico, para que se promova um aumento na produtividade das atividades tanto do designer como do modelista nas etapas preliminares de projeto.

Mesmo nos aspectos que geraram pontos mais polêmicos quanto à discussão do desenho técnico do vestuário junto aos profissionais da área de modelagem, como no caso se sua visualização deveria ser considerada como sendo o produto representado esticado sobre superfície plana ou sobre o corpo, a divisão de opiniões demonstrou que é preciso repensar melhor os métodos e as alternativas para o desenvolvimento do desenho técnico, no intuito de contemplar ambas as linhas de pensamento para deixar de lado atitudes segmentadas que impõem princípios de construção embasados em condições meramente intuitivas ou particulares sem levar em consideração as reais necessidades do receptor da mensagem gráfica responsável pela materialização do produto, ou seja, o profissional da área de modelagem.

Ainda nesse sentido, observa-se a possibilidade de propor posteriormente, dois métodos diferenciados para a construção do desenho técnico do vestuário que contemplem as exigências daqueles que preferem fazer a interpretação do modelo visualizado esticado sobre superfície plana e daqueles que consideram melhor interpretá-lo sobre o corpo.

Com relação às analogias utilizadas na representação do desenho técnico do vestuário vindas de outras áreas do conhecimento, como por exemplo a teoria projetiva, mais importante do que julgar o valor de sua aplicação, é refletir sobre a possibilidade de se capacitar melhor os designers de moda e os próprios modelistas durante o processo de aprendizado já nas instituições de ensino. Tal argumento apóia-se no fato de que os mesmos devem estar aptos a utilizar esses princípios e fundamentos de forma consciente para apresentar soluções tanto 
O desenho técnico do vestuário sob a ótica do modelista

nos aspectos bidimensionais como tridimensionais na representação gráfica do produto para evitar agir somente pelo raciocínio meramente intuitivo e consolidar as iniciativas que buscam a profissionalização da área.

No que se refere à dificuldade da leitura e da interpretação do desenho técnico que existe hoje entre os profissionais da área, e que geram problemas de comunicação no processo de desenvolvimento de produtos, é importante ressaltar que as ações das várias pesquisas que buscam pela sua melhoria no âmbito científico devem, na medida do possível, serem testadas e aplicadas de forma mais rápida para não ficar apenas no discurso reflexivo.

Uma vez que os recursos e as tecnologias computacionais, tanto em equipamentos como programas gráficos direcionados para o desenvolvimento do desenho, torna-se uma realidade cada vez mais presente no nosso dia-a-dia, é necessário que as bases para a construção do desenho técnico do vestuário sejam aplicadas gradativamente, mesmo com o risco de aparecer resultados equivocados nesse sentido. É preferível que isso aconteça o quanto antes, pois assim reformulações dos conceitos de construção do desenho técnico do vestuário podem ser corrigidas mais cedo, proporcionando posteriormente uma extensão mais adequada junto aos avanços tecnológicos existentes.

\section{Referências}

ARAÚJO, Mário. Tecnologia do Vestuário. Lisboa: Fundação Calouste Gulbenkian, 1996.

ABLING, Bina. Fashion sketchbook. 2. ed. New York: Fairchild Publications, 1995.

BELTRAME, Giampaolo. I/ disegno del figurino di moda. Italia: Editoriale Paradigma, 1990.

BERENGUER, Maria J. Forcadell; PASTOR, Josep Asunción. Desenho para joalheiros. Lisboa: Editorial Estampa, 2004.

CASTILHO, Kathia. Moda e linguagem. 2. ed. São Paulo: Ed.Anhembi Morumbi, 2004.

CHING, Francis D. K. Representação gráfica em arquitetura. 3. ed. Porto Alegre: Bookman, 2000.

DRUDI, Elisabetta; PACl, Tiziana. Dibujo de figurines para el diseño de moda. Amsterdam: The Pepin Press, 2001.

FERREIRA, Luciane Gago Duro. Dificuldade de representação gráfica em alunos de nível universitário. In: CONGRESSO BRASILEIRO DE PESQUISA E DESENVOLVIMENTO EM DESIGN $P \& D, 7,2006$, Curitiba. Anais... Curitiba: AEnD-BR, 2006. 10p CD-Rom.

FRENCH, Thomas E.; VIERCK, Charles J. Desenho técnico e tecnologia gráfica. 7. ed. São Paulo: Editora Globo, 2002.

FULCO, Paulo de Tarso; SILVA, Rosa L. de Almeida. Modelagem plana feminina. Rio de Janeiro: Ed. Senac Nacional, 2003.

GIESECKE, Frederick E.; MITCHELL, Alva; SPENCER, Henry Cecil; HILL, Ivan Leroy; DYGDON, John Thomas; NOVAK, James E.; LOCKHART, Shawna. Comunicação gráfica moderna. Porto Alegre: 
Bookman, 2002.

GIL, Antonio Carlos. Métodos e técnicas de pesquisa social. 5. ed. São Paulo: Editora Atlas, 2006.

GRAVE, Maria de Fátima. A modelagem sob a ótica da ergonomia. São Paulo: Zennex Publishing, 2004.

JONES, Sue Jenkyn. Fashion design: manual do estilista. São Paulo: Cosac \& Naify, 2005.

LAFUENTE, Maite. Ilustración de moda. Madri: H Kliczkowski-Onlybook, 2005.

LEITE, Adriana Sampaio; VELLOSO, Marta Delgado. Desenho técnico de roupa feminina. Rio de Janeiro: Ed. Senac Nacional, 2004.

ROSA, Lucas da; FREITAS, Neli Klix. Percepção e criatividade na confecção do produto de moda. ModaPalavra, Florianópolis, v. 3, n. 3, 2004.

SHIMURA, Kisashi. Fashion drawing technique. Japan: Butikku, 2002.

TAIN, Linda. Portfolio presentation for fashion designers. New York: Fairchild Publications, 1998.

TAKAMURA, Zeshu. Fashion with style. Japan: Graphic-Sha Publishing, 1993. 